\title{
Effects of biofuels properties on aircraft engine performance
}

\author{
Abstract \\ Purpose - The purpose of this paper is to examine the effects of heat capacity and density of biofuels on aircraft engine \\ performance indicated by thrust and fuel consumption.
}

Design/methodology/approach - The influence of heat capacity and density was examined by simulating biofuels in a two-spool high-bypass turbofan engine running at cruise condition using a Cranfield in-house engine performance computer tool (PYTHIA). The effect of heat capacity and density on engine performance was evaluated through a comparison between kerosene and biofuels. Two types of biofuels were considered: Jatropha Bio-synthetic Paraffinic Kerosene (JSPK) and Camelina Bio-synthetic Paraffinic Kerosene (CSPK).

Findings - Results showed an increment in engine thrust and a reduction in fuel consumption as the percentage of biofuel in the kerosene/biofuel mixture increases. Besides a low heating value, an effect of heat capacity on increasing engine thrust and an effect of density on reducing engine fuel consumption are observed.

Practical implications - The utilisation of biofuel in aircraft engines may result in reducing over-dependency on crude oil. Originality/value - This paper observes secondary factors (heat capacity and density) that may influence aircraft engine performance which should be taken into consideration when selecting new fuel for new engine designs.

Keywords - Biofuels, heat capacity, density, aircraft engine performance, thrust, fuel consumption

\section{Paper type - Technical paper}

\section{Introduction}

Extensive growth in airlines industry contributes to the problem on the increases of conventional fuel price due to high demand on this fuel. Additionally the growth also contributes to the increases in pollution emission emitted into the atmosphere. Clercq and Aigner (2009) emphasized two approaches to address the problems: (1) By improving the overall aircraft energy efficiency and (2) By finding alternatives to crude/conventional fuel. The first approach may be quite challenging as it requires new aircraft and propulsion system design and new operation strategies but the second option might be less challenging. However attention must be given to issues of fuel sustainability and fuel properties which could possibly affect the performance of the engines and aircraft.

Dagget et al. (2006) and Demirbas (2007) highlighted different types of alternative fuel that might be candidates towards the replacement of conventional fuel, namely hydrogen fuel $(\mathrm{H} 2)$, other liquefied fuels (such as propane and butane), alcohols (such as ethanol and methanol), biofuels (combustible liquid manufactured from renewable sources such as animal fats and plants oils), and synthetic fuels (fuel produced from synthesis process, such as Fischer-Tropsch process). As mentioned above the challenges in choosing a new fuel are whether that fuel is sustainable and if the modification to the engine is required. The sustainability of the crops to produce the biofuel is important to ensure the production of the feedstock is not interfering with food or freshwater supply (O'Keeffe, 2010) and therefore contributes to higher food prices due to the competition with food crops (Sims et al, 2008). Other aspect that becomes concern is to ensure that the biofuels will not cause any anthropogenic issues through deforestation during the creation of sufficient farm land capacities (Dagget et al, 2007). In regard to properties of the biofuels, energy content, combustion stability and freeze point, etc. should be carefully assessed. In terms of low energy content, ethanol for example requires $64 \%$ more 
storage volume to provide same amount of energy compared with kerosine. Consequently about $25 \%$ larger wings may be required to carry the fuel, which therefore may result in an increase of airplane's empty weight by $20 \%$ and take-off weight by 35\% (Dagget et al, 2006). In addressing thermal stability issue and tendency of the fuel to freeze, Dagget et al (2006) suggested new technology in relation to fuel processing which converting bio-derived oil rich with triglycerides and free fatty acids into biojet fuel, which has the composition of molecules already present in jet fuel. Through this technology, the new fuel will have higher heating value and improvement in thermal stability and freezing point. Moreover, blend biofuels with kerosene becomes an option to alleviate those anxieties as characteristics of the fuel not only can be improved but the fuel also can be utilised in the existing aircraft engines with no modifications required (Dagget et al, 2006).

\section{Literature Review}

Blend fuels also termed as "drop-in" fuels (Dagget et al, 2007) or "fit-for-purpose" fuels (Clerq and Aigner, 2009) have been proposed and utilised during 2008-2009. There were three flight tests carried out in order to ascertain the capability of in the blend fuels in existing aircraft engines. In 2008 Air New Zealand's Boeing 747-400 aircraft flew successfully with one of its four Rolls-Royce RB211-524 engines running with a 50\% blend of Jatropha with Jet-A-1 (Rahmes et al, 2009) although no significant changes in performance were revealed (Warwick, 2009). In 2009, another successful test flight was carried out by Japan Airlines, where a Boeing 737-300 flew using a mixture of 50\% biofuel (42\% Camelina, and $8 \%$ of the mixture of Jatropha and algae) with $50 \%$ kerosene in one of the Pratt \& Whitney JT9D-7R4G2 engines (Rahmes et al, 2009). Similarly, no difference in engine performance was detected. Furthermore, Continental Airlines flew a Boeing 737-800 aircraft where one of its engines (CFM56-7B) used a mixture of $47.5 \%$ Jatropha and $2.5 \%$ algae with conventional jet fuel (Rahmes et al, 2009). The flight test was successful although no difference in performance was found. To summarise, all flight tests were successful but improvement in engine performance was neglectable.

In an attempt to understand the effects of adding biofuels to Jet-A on engine performance, an experimental study was conducted by (Habib et al, 2009) using soy methyl ester (SME), canola methyl ester (CME), recycled rapeseed methyl ester (RRME) and hog-fat (HF) fuel, which had been tested in pure form (100\% or B100) and as blends (50\% by volume, B50) with Jet-A in a small-scale (30 kW) gas turbine. The authors noticed almost a linear reduction of static thrust with engine speed for all fuels, and the measurements of all fuels feel within the experimental uncertainties except for RRME, which did not follow the trend; however, no explanation was offered for this result. Except for RRME, reduction in static thrust was observed due to lower heating values of biofuel (nearly $10 \%$ lower) in comparison to Jet-A which consequently reduces the available energy to produce thrust. Moreover, adding biofuels to Jet-A provided no significant differences in thrust specific fuel consumption (TSFC) as well as in thermal efficiency. Pure biofuels showed slightly lower TSFC and higher thermal efficiencies than Jet-A. Higher thermal efficiencies of gas turbine due to using B100 biofuels are believed to be the presence of oxygen molecules in the biofuel. Measurements of turbine inlet temperature for pure biofuels were found to be slightly lower than Jet-A at low speeds, but were nevertheless close to Jet-A at high speeds. However, exhaust gas temperatures for all fuels were found to be very similar to each other (Habib et al, 2009)

During the same year, Rahmes et al (2009) conducted off-wing engine ground tests in order to evaluate the impact of Jatropha and algae-derived bio-synthetic paraffinic kerosine on engine performance and emissions. The test was carried out on a CFM56-7B engine, which was first run with Jet-A, followed by a $25 \%$ and then $50 \%$ blend of Bio-SPK fuel. It was noted that increases in the blending percentage of Bio-SPK improved the specific fuel consumption and fuel flow. Both $25 \%$ and $50 \%$ Bio-SPK blends showed reduction in fuel flow by $0.7 \%$ and $1.2 \%$, respectively, and were found to be consistent with differences in the heat of combustion ( $0.6 \%$ for the $25 \%$ blend and $1.1 \%$ for the $50 \%$ blend). 
Mazlan et al (2012) conducted a numerical study to evaluate the amount of thrust and the amount of fuel consumed by a two-spool high-bypass turbofan engine which was run on pure biofuel and on mixtures of $10 \%$ and $50 \%$ of the tested biofuels with Jet-A. The biofuels used in this work were JSPK and CSPK. Increases in engine thrust were observed as the percentage of biofuel in the mixture increased.. The highest thrust is produced when the engine runs with $100 \%$ biofuel, which is due to the low heating value (LHV) of the fuel being the highest among the fuels/fuel blends tested. In addition to an improvement in engine thrust, a biofuel blend with Jet-A was also observed to improve the fuel flow rate by approximately $0.3 \%$ (10\% biofuel, $90 \%$ Jet-A) to $2.3 \%$ (100\% biofuel) (Mazlan et al, 2012). Both of the studies conducted by Rahmes et al (2009) and Mazlan et al (2012) have shown the effect of LHV on engine thrust.

\section{Overview of present work}

This present study is conducted as an extension of Mazlan et al (2012) but focuses on heat capacity and density as secondary factors that might influence engine thrust and fuel consumption. This study evaluates the performance of a turbofan engine running with JSPK $\left(\mathrm{C}_{12} \mathrm{H}_{26}\right)$ and CSPK $\left(\mathrm{C}_{12} \mathrm{H}_{24.5}\right)$ (Mazlan et al, 2012), as a pure fuel and as blend with Jet-A at $20 \%, 40 \%, 60 \%$ and $80 \%$, in order to find a correlation between engine performance and the percentage of the biofuel in the mixture. Additionally, despite LHV being the major factor influencing engine thrust this study investigates the effect of other fuel properties, namely, the effect of the fuel's heat capacity and density on engine thrust and fuel consumption respectively. To investigate the effect of the heat capacity and density only pure JSPK and pure CSPK are used and a comparison between these biofuels and Jet- $A$ is performed. The evaluation is performed using a Cranfield inhouse engine performance (PYTHIA) computer program where a set of calorific properties of fuel generated by NASA Chemical Equilibrium with Application (CEA) (McBride, J. B. and Gordon, S., 1996) have been implemented. Due to limited data available in NASA CEA's library, Mazlan et al (2012) generated the calorific properties of the selected biofuels by introducing NASA CEA with the predicted molecular formula and heat of formation of the fuels while a comparison of this data with the nearest molecular formula available in literature was performed to assess whether it is reasonable and dependable to be used in PYTHIA. The assessment recorded low percentage of differences (1\%) and therefore considered acceptable.

\section{Overview of Computer Tool Used}

PYTHIA is a computer program developed at Cranfield University, UK over 30 years ago. This program is able to execute performance calculations for both design points and off-design points for any types of open-cycle engines. In addition, this program is also considered user-friendly because users are only required to prepare the input file, which describes the engine configuration and the parameters for each of the engine components ( $\mathrm{Li}$ and Singh (2005)). The capability of PYTHIA in calculating engine performance has recently been improved due to a study conducted by Kamunge (2011), who introduced and developed a theoretical method that is able to generate fuel properties such as heat capacity over a wide range of temperature. This method was introduced due to the earlier limitation of PYTHIA, where the value of heat capacity was based on the experimental set-up and ambient temperature measurements. Although the value obtained through the experiment is very precise, the value is restricted to a certain range of temperature. Additionally, in the early stages of PYTHIA development, the gas property calculation was based on kerosene fuel so the performance calculation was limited to the use of single fuel. Kamunge (2011) successfully introduced new fuel property models for multiple fuels. Additionally, Kamunge (2011) also includes a dissociation effect into PYTHIA to increase the accuracy of PYTHIA in

calculating engine performance. According to Kamunge (2011) dissociation effects become noticeable at high temperatures (above $1200 \mathrm{~K}$ ) and/or low pressures. If these effects are neglected, this can lead to significant deviations in the calculation of caloric properties, especially of $C_{p}$ and $\gamma$. In addition to sensitivity to high temperature and low pressure, 
caloric properties also are sensitive to the ratio of hydrogen and carbon atom $(\mathrm{H} / \mathrm{C})$. Therefore, neglecting the effect of fuel chemistry on the caloric properties calculation (by assuming non-dissociation effects) may also lead to significant simulation errors.

\section{Engine Parameter}

In evaluating the performance of the engine in the present study, a model of two spool high bypass turbofan engine considered in Mazlan et al (2012) was used.Engines similar to this model engine are widely used in most of modern civil aircraft and more fuel-efficient compared to other types of engines. It was assumed that the assessment of engine design selections of the model engine was at cruise condition with the baseline engine design parameters presented in Table. 1. This data was partly obtained from public domain and partly assumed based on data obtained in public domain.

Table 1: Engine Characteristics (Mazlan et al, 2012)

\begin{tabular}{lcc}
\hline \hline Parameter & Unit & Value \\
\hline \hline Altitude & $\mathrm{m}$ & 10668 \\
$\mathrm{~W}$ & $\mathrm{~kg} / \mathrm{sec}$ & 130 \\
$\mathrm{M}$ & & 0.8 \\
TET & $\mathrm{K}$ & 1660.0 \\
BPR & & 5.46 \\
FPR & & 1.8 \\
IPCPR & & 1.811 \\
HPCPR & & 10.0 \\
OPR & & 32.6 \\
Power taken from HPT & $\mathrm{kW}$ & 200 \\
\hline \hline
\end{tabular}

\section{Engine Performance Validation}

To check the reliability of PYTHIA in evaluating engine performance provided with biofuels calorific properties data, the investigation on the relationship between consuming fuel flow with LHV for $50 \%$ biofuel with $50 \%$ kerosene mixture was performed. The results was compared with experimental work from Rahmes et al., (2009) who conducted an off-wing engine ground test for $50 \%$ Jatropha-Algae $/ 50 \%$ Jet-A. It appears that, the fuel blend used in this off-wing engine ground test was not similar to that evaluated in this work, although they are of the same family. The fuel used in the off-wing ground test is a mixture of two bio-SPK fuels with Jet-A, while fuel used in this research is a mixture of one bio-SPK fuel with Jet-A. However, the total composition of bio-SPK fuel in the mixture was taken as the same. Although the fuel mixture in the literature is different to the one used in this work, it is not expected to have significant difference in the trends.

Figure 1 shows the percentage difference of fuel flow reduction and percentage difference of increased LHV with respect to Jet-A over the fuels used in this work and in the literature. It is observed that the reduction of fuel flow expected from this research work is consistent with the reduction of fuel flow predicted in the literature. As expected, the relationship between the fuel flow reductions predicted in this research work is consistent with the increases of LHV as predicted in the literature. This comparison assessment summarises that the calculated molecular formula and enthalpy of formation used in generating the caloric properties data as the input for PYTHIA can be relied upon and the capability of PYTHIA of conducting the engine performance evaluation is dependable. 


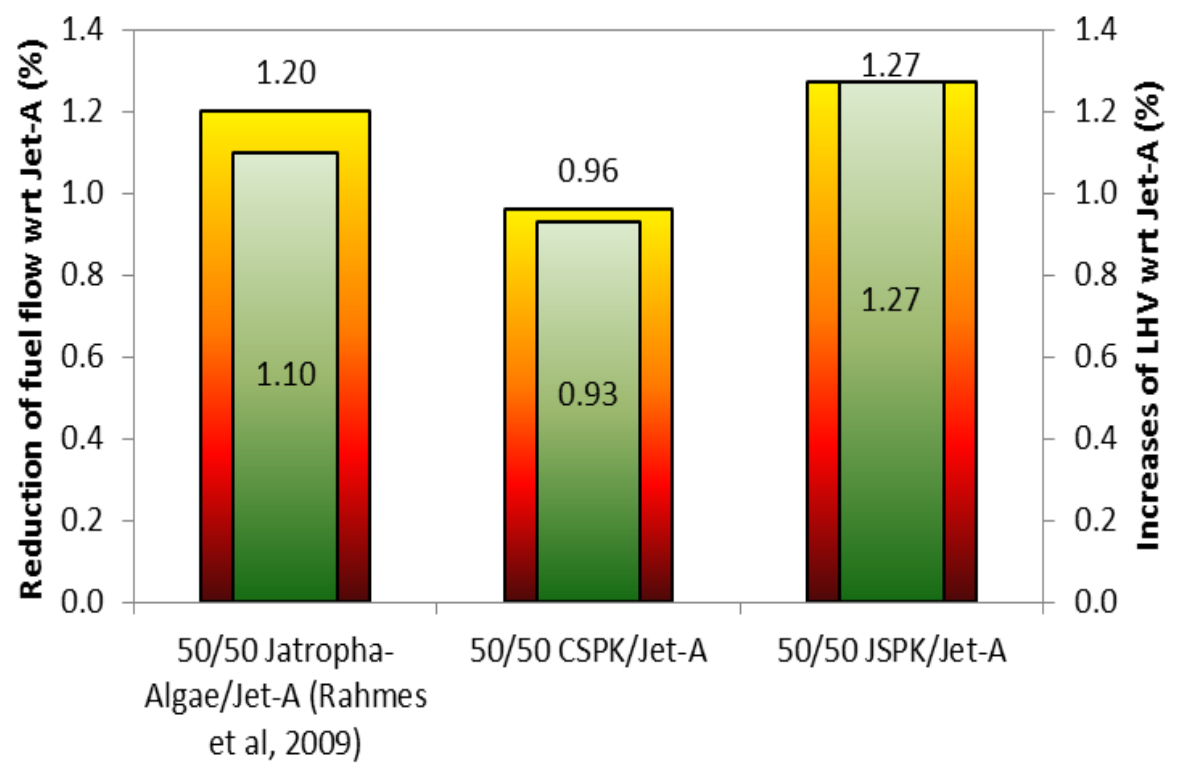

口Fuel flow 口LHV

Figure 1: The comparison of Fuel flow and Heating Value with Literature

\section{Influence of Biofuel Mixture}

Figure 2 shows the percentage difference of engine thrust, fuel consumption and specific fuel consumption (SFC) predicted for the implementation of CSPK either as a pure or by blend with Jet-A in a two-spool high-bypass turbofan engine. Figure 3 shows the results in respect of JSPK. Both fuels showed the same trend in terms of predicted thrust, fuel flow and SFC. Specifically, in comparison to Jet-A, CSPK and JSPKshowed an increase in thrust, a reduction in fuel flow and an improvement in SFC, although the improvement was considered to be small and not significant. The same trend was also observed as the proportion of bio-SPK fuel in the blend increased. The highest increase in thrust, largest reduction of fuel flow and greatest improvement in SFC were observed when 100\% of bio-SPK fuel was used. When both fuels were compared, it was observed that CSPK provided a greater improvement in thrust (0.12\%) compared to JSPK $(0.09 \%)$. However, the use of JSPK improved the results for fuel flow and SFC of the two-spool high-bypass engine simulated at the design point condition by $2.31 \%$ and $2.39 \%$, respectively, as opposed to CSPK, which improved fuel flow and SFC by $1.69 \%$ and $1.80 \%$, respectively. 


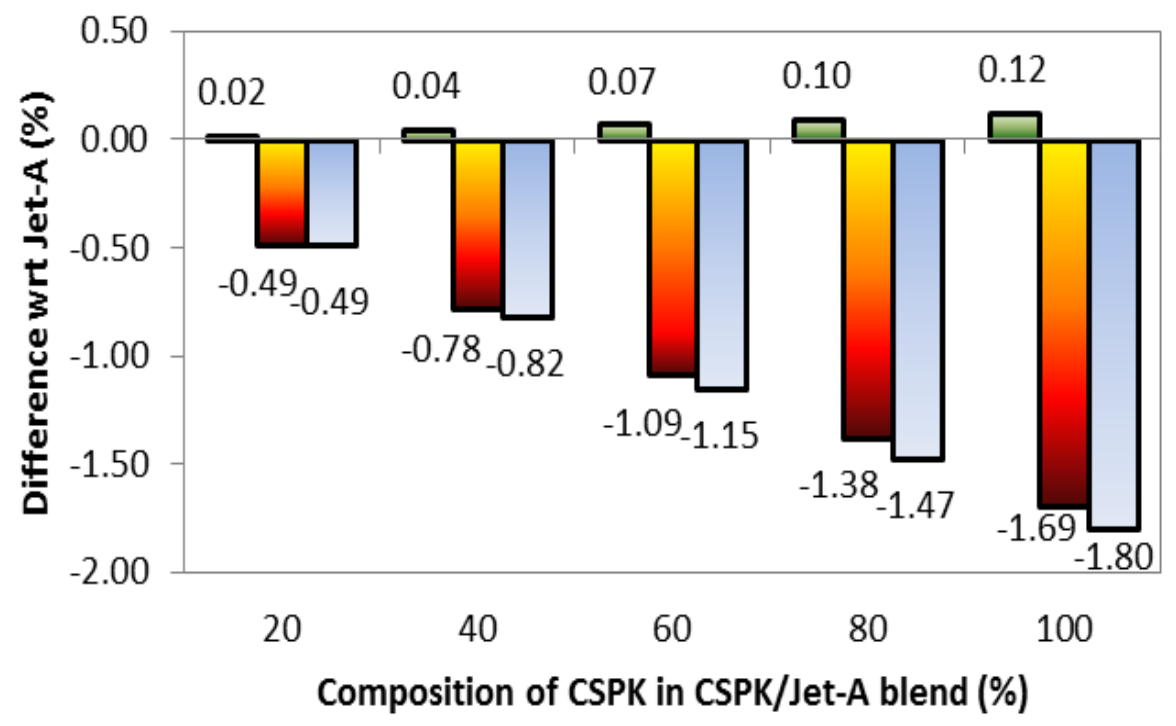

口THRUST GFUEL FLOW Q DSFC

Figure 2: Comparison of Thrust, Fuel Flow, and SFC of Pure CSPK and CSPK/Jet-A blend with Jet-A

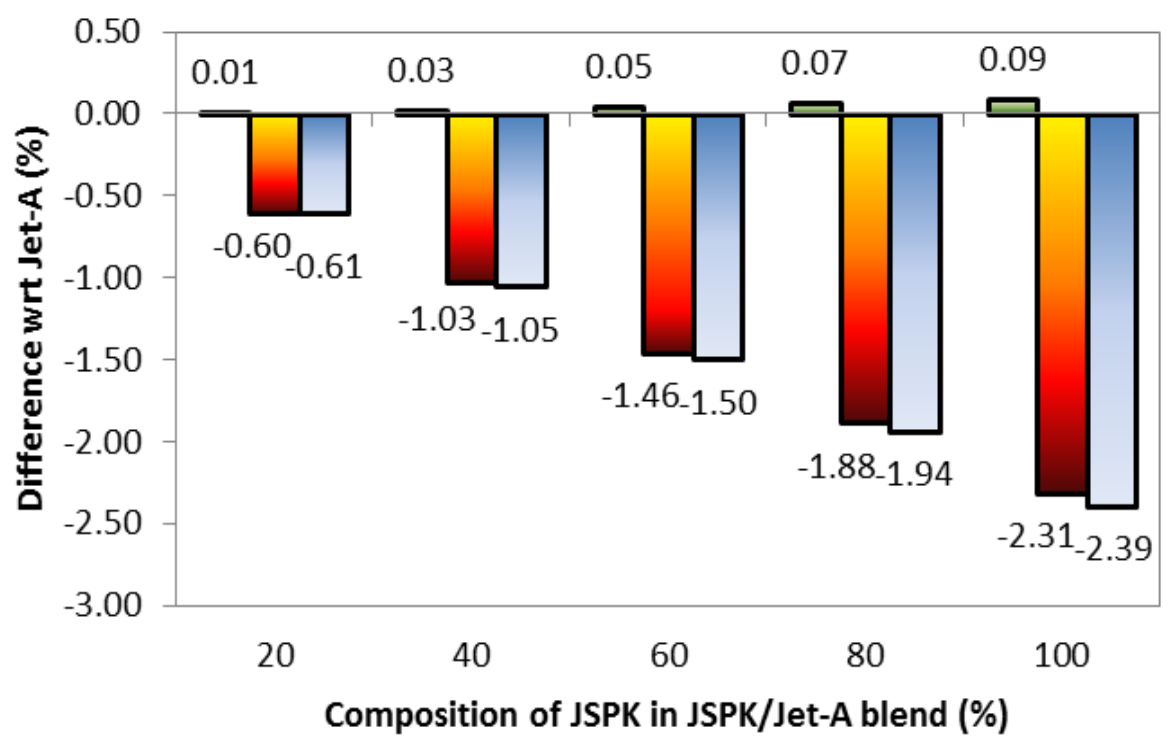

口THRUST Q GEUEL FLOW םSFC

Figure 3: Comparison of Thrust, Fuel Flow, and SFC of JSPK/Jet-A blend with Jet-A

\section{Effect of Heat Capacity of the Fuel and air Combustible Mixture on Engine Thrust}

As known, LHV becomes an utmost factor that influence engine thrust. Besides LHV, heat capacity of the combustible mixture (fuel and air) $\left(C_{p}\right)$ could be another factor that might affect the amount of thrust generated by an aircraft engine. As can be observed in Fig. 4, the thrust generated by CSPK and JSPK was higher than Jet-A. As reported in Mazlan et al (2012), increases in engine thrust was due to the increases in the LHV. However, the comparison between both selected biofuels showed that the thrust generated by $100 \%$ CSPK was slightly higher than that generated by $100 \%$ JSPK (i.e., by $0.03 \%$ ). Hence, although the LHV of JSPK is higher than that of CSPK (JSPK $=44.3 \mathrm{MJ} / \mathrm{kg}$ and CSPK $=44.0 \mathrm{MJ} / \mathrm{kg}$ ), it appears that LHV itself is not only the factor influencing thrust generation. In the present study, the effect of heat capacity of fuel and air combustible mixture on engine thrust was observed. In order to check the effect of heat capacity on engine 
thrust, the simulation was performed in which the fuel flow was fixed while the other parameters were unchanged. Heat capacity of combustible mixture for fuel selected in this study was predicted using NASA CEA which measured at constant fuel air ratio (FAR) of $1.65 \%$ which is equivalent to equivalence ratio of 0.25 . It was observed that in comparison to CSPK, increasing $0.034 \%$ of heat capacity of JSPK/air combustible mixture increased thrust by about $0.34 \%$.

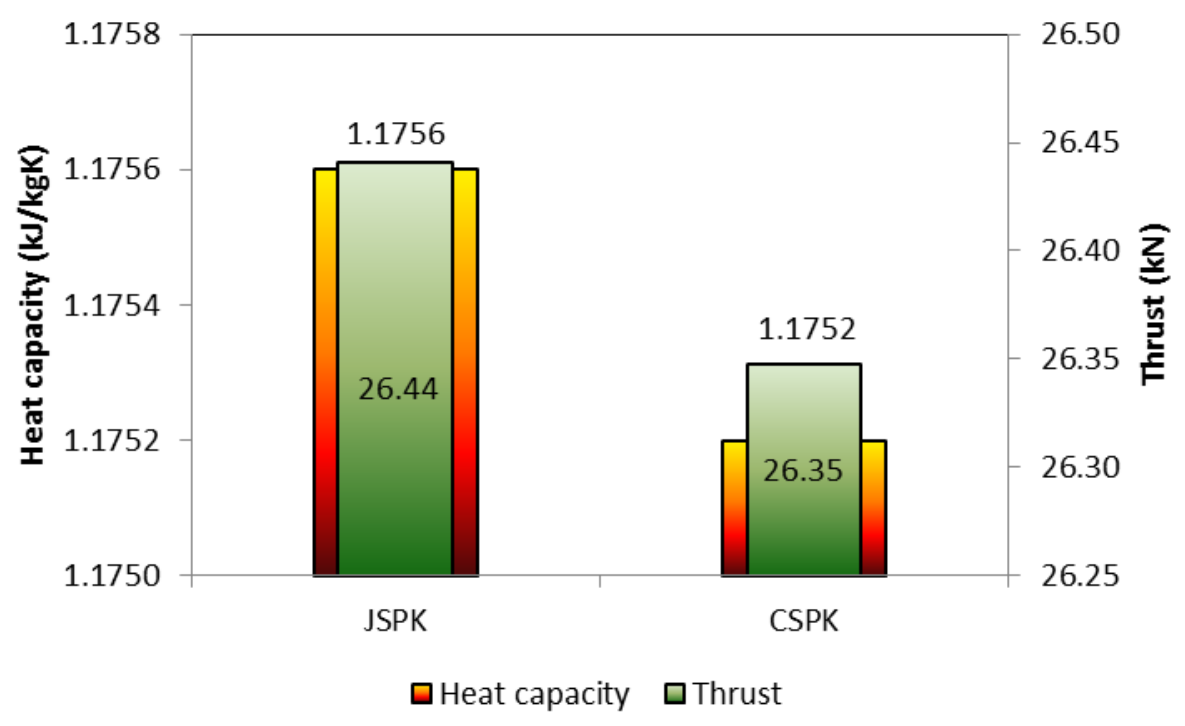

Figure 4: Effect of Heat Capacity on Engine Thrust

According to Mattingly (1996), the thrust of a turbofan is a total of the thrust generated from the core stream and the thrust from the fan stream as presentedaccordingly inEq (1).

$$
F=\frac{\dot{m}_{C}}{g_{c}}\left(V_{9}-V_{0}\right)+\frac{\dot{m}_{F}}{g_{c}}\left(V_{19}-V_{0}\right)
$$

where $\mathrm{F}$ is thrust $(\mathrm{N}), \mathrm{g}_{\mathrm{c}}$ is gravity constant, and $\dot{m}_{c}$ and $\dot{m}_{F}$ are the mass flow rate of the core stream and of the fan stream, respectively $(\mathrm{kg} / \mathrm{s})$, while $\mathrm{V}_{0}, \mathrm{~V}_{9}$, and $\mathrm{V}_{19}$ are initial velocity, core exit velocity and fan exit velocity (m/s), respectively.

On the other hand, core exit velocity, $\mathrm{V}_{9}$ can be presented as in $\mathrm{Eq}(2)$, where the correlation between the velocity and turbine temperature ratio is shown as follows:

$$
\frac{V_{9}}{a_{0}}=\sqrt{\frac{2}{(\gamma-1)} \frac{\tau_{\lambda}}{\tau_{r} \tau_{c}}\left(\tau_{r} \tau_{c} \tau_{t}-1\right)}
$$

where $\mathrm{y}$ is gamma, $\tau_{\lambda}$ is the ratio of the burner exit enthalpy to the ambient enthalpy, $\tau_{c}$ is the compressor temperature ratio, $\tau_{r}$ is the ratio of total to static temperature of the free stream, and $\tau_{t}$ is the turbine temperature ratio. Ratio of the turbine temperature can be calculated from energy balance equation as shown in Eq (3).

$$
\dot{W}_{t}=\left(\dot{m}_{C}+\dot{m}_{f}\right) c_{p}\left(T_{t 4}-T_{t 5}\right) \cong \dot{m}_{0} c_{p} T_{t 4}\left(1-\tau_{t}\right)
$$

In Eq. 3, $\dot{W}_{t}$ is the turbine power (Watt), $\mathrm{C}_{\mathrm{p}}$ is the heat capacity of the combustible mixture (fuel and air), $\mathrm{T}_{\mathrm{t} 4}$ and $\mathrm{T}_{\mathrm{t} 5}$ are the temperature at the turbine inlet and at the outlet, respectively, $(\mathrm{K})$, and $\dot{m}_{0}$ is total mass flow rate $(\mathrm{kg} / \mathrm{s})$. 
Rearrange Eq (3), the relationship between turbine temperature ratio with turbine work and heat capacity can be determined (Eq (4)). Considering the turbine work, total mass flow and TET are known, therefore turbine temperature ratio depends only on heat capacity.

$$
\tau_{t}=\frac{T_{t 5}}{T_{t 4}}=1-\frac{\dot{W}_{t}}{\dot{m}_{0} C_{p} T_{t 4}}
$$

Therefore as $C_{p}$ increases, the turbine temperature ratio increases consequently increase the velocity and engine thrust. Although the increases are not significant, in order to compare the effect of the fuels, the contribution of heat capacity has to be taken into account.

\section{Effect of Fuel Density on Fuel Consumption}

The evaluation of the effect of density on fuel consumption showed that the fuel consumed by the engine increases with increases in fuel density (Fig. 5). A simulation of the engine running with biofuels (low-density fuel) revealed that less fuel is consumed than when running the engine with Jet-A. As shown in Fig. 4, an engine running with JSPK with a density difference that is about $7.7 \%$ lower than Jet-A consequently consumed about $2.3 \%$ less fuel than when running on Jet- $A$, while for CSPK, the fuel consumed was about $1.6 \%$ lower which resulted from a $7.4 \%$ lower density compared to Jet-A.

In the present study, the simulation was performed in a condition where the turbine entry temperature (TET) value was set and kept constant for all types of fuel. Therefore, in order to accommodate the TET, the fuel injector had to inject a larger mass of dense fuel due to its low energy content, while in contrast, only a small quantity of mass had to be injected for the less dense fuel. This is advantageous in terms of achieving a reduction in fuel consumption.

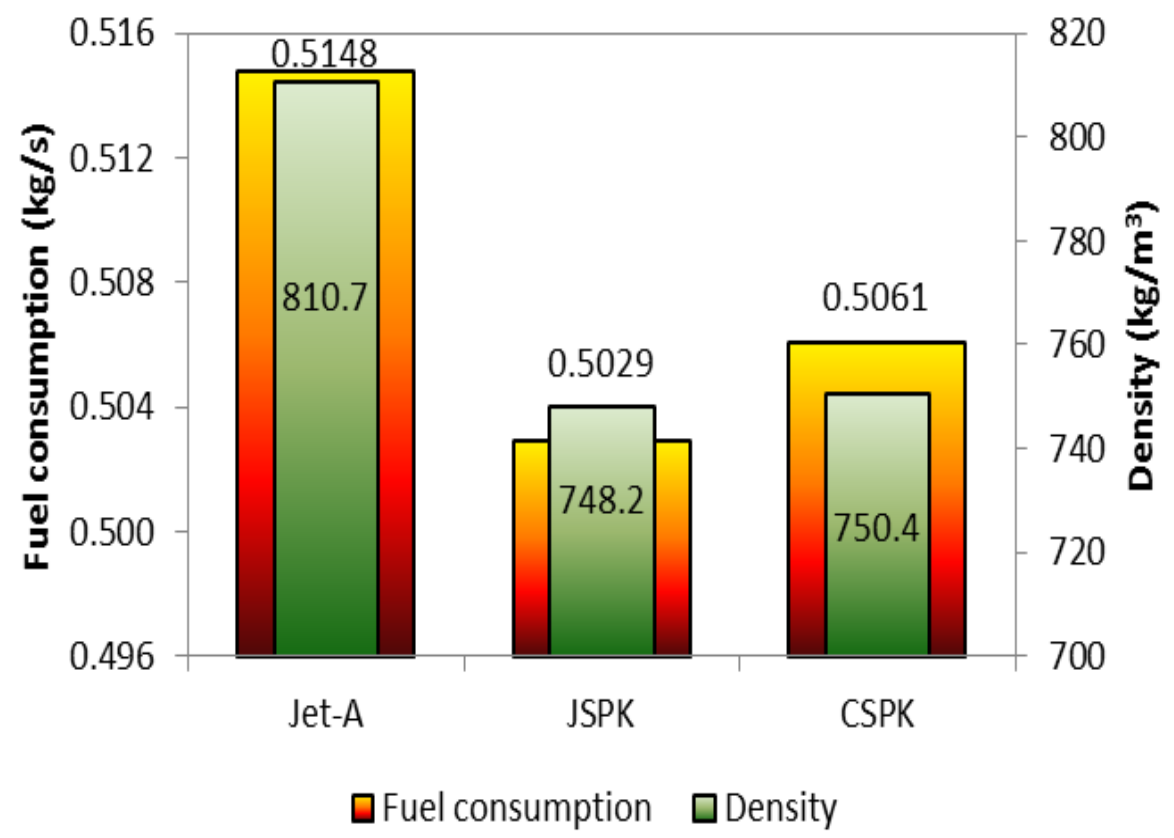

Figure 5: Effect of Fuel Density on Fuel Consumption

\section{Conclusion}

The present study assessed the performance of two-spool high-bypass turbofan engines running with Bio-Synthetic Paraffinic Kerosine (bio-SPK) fuel, namely, Jatropha Bio-Synthetic Paraffinic Kerosine (JSPK) and Camelina Bio- 
Synthetic Paraffinic Kerosine (CSPK). The assessment was conducted with $100 \%$ of bio-SPK fuel and with blends at $20 \%, 40 \%, 60 \%$, and $80 \%$ of the biofuel with $80 \%, 60 \%, 40 \%$ and $20 \%$ of Jet-A, respectively. An evaluation and comparison of the thrust, fuel flow, and specific fuel consumption (SFC) of pure bio-SPK fuels and their blends with Jet-A were presented. Additionally the secondary factors that effect the engine performance were discussed. Results obtained showed that both bio-SPK fuels produce more thrust than Jet-A. The improvement of engine performance increases almost linearly as the percentage of biofuel in the mixture increases. For each bio-SPK fuel, the highest thrust is produced by implementing $100 \%$ of the fuel in the engine. However, CSPK is found to generate higher thrust than JSPK. The implementation of bio-SPK fuels in the aircraft engine either at $100 \%$ or by blending with Jet- $\mathrm{A}$ is observed to reduce the consumption of fuel and improve the SFC which consequently improves (increases) efficiency. Similarly with thrust, the highest reduction in fuel flow is found when the engine is running with $100 \%$ bio-SPK fuel. However, the highest reduction of fuel flow is observed when $100 \%$ of JSPK is used. Although it was known that LHV is the important factor that effect the engine thrust, the effect of heat capacity on engine thrust also is observed.The comparison of heat capacity of combustible mixture between the selected biofuels have shown the effect of this variable on engine thrust as it provides high velocity at the nozzle exit consequently increases engine thrust. In addition, the effect of density is also observed to influence the reduction of fuel flow during the design point condition. This is because the fuel injector has to inject a greater quantity of higher-density fuel than lower-density fuel. As a conclusion, assessments conducted in this present study have shown the capability of bio-SPK fuel to provide an improvement in engine performance.

\section{Further Work}

The current multi-fuel version of PYTHIA is limited to design point computations for individual engine configurations with a specific selected fuel, and so changes in fuel composition can also have an effect on the other engine design point conditions. In order to avoid this possibility in comparing the variation of performance with different fuel blends, a more general off-design capability is required, and this is presently the subject of further development by biofuel is essential.

\section{Acknowledgements}

The authors are grateful to their close Cranfield colleague Dr.Li for making available the PYTHIA code, and for his advice and assistance in using the multi-fuel version of this that he has been developing.

\section{References}

Dagget, D. L., Hendricks, R. C., Walther, R. and Corporan, E. (2007), "Alternate Fuels for use in Commercial Aircraft", The Boeing Company.

Dagget, D., Hadaller, O., Hendricks, R., Walther, R., (2006), "Alternative Fuels and Their Potential Impact on Aviation", The $25^{\text {th }}$ Congress of the International Council of the Aeronautical Sciences (ICAS) hosted by the German Society for Aeronautics and Astronautics, Vol. NASA/TM-2006-214365, September 3-8, 2006, Hamburg, Germany, pp. 1 - 8.

Demirbas, A. (2007), "Progress and Recent Trends in Biofuels", Progress Energy Combust Sci, vol. 33, pp. 1-18.

Habib, Z., Parthasarathy, R. and Gollahalli, S. (2009), "Performance and Emission Characteristics of Biofuel in a Smallscale Gas Turbine Engine", Applied Energy, vol. 87, no. 5, pp. 1701-1709 
Kamunge. D., (2011), "A non-linear weighted least squares gas turbine diagnostic approach and multi-fuel performance simulation", PhD thesis, Cranfield University

Le Clercq, P., Aigner, M., (2009), "Impact of Alternative Fuels Physical Properties on Combustor Performance", 11th Triennial International Annual Conference on Liquid Atomization and Spray Systems, (ICLASS), Vail, Colorado, USA

Li Y.G. and Singh R.,(2005), “An Advanced Gas Turbine Gas Path Diagnostic System - PYTHIA”, ISABE-2005-1284, the Seventeenth International Symposium on Airbreathing Engines (17 ${ }^{\text {th }}$ ISABE), Munich, Germany, September 2005.

Mattingly, J. D. (1996), “Elements of Gas Turbine Propulsion”, McGraw-Hill Inc.

Mazlan., N. M., Savill., M., Kipouros., T., Li. Y. G., (2012), "A Numerical Study into the Effects of Bio-Synthetic Paraffinic Kerosine Blends with Jet-A Fuel for Civil Aircraft", GT2012 - 68754, Proceedings of ASME Turbo Expo 2012, June 11-15, 2012, Copenhagen, Denmark.

McBride, J. B. and Gordon, S., (1996), "Computer Program for Calculation of Complex Chemical Equilibrium Compositions and Applications", User's Manual and Program Description. NASA Washington DC: NASA Lewis Research Center, NASA Report NASA RP-1311-P2: June, 1996

O'Keeffe, N., (2010), Planting hope, Flight International magazine, 23 February-1 March 2010, p 28, website: www.flightglobal.com

Rahmes, T. F., Kinder, J. D., Henry, T., M., Crenfeldt, G., LeDuc, G. F., Zombanakis, G. P., Abe, Y., Lambert, D. M., Lewis, C., Juenger, J. A., Andac, M. G., Reilly, K. R., Holmgren, J. R., McCall, M. J. and Bozzano, A. G. (2009), "Sustainable Bio-Derived Synthetic Paraffinic Kerosine (Bio-SPK) Jet Fuel Flights and Engine Tests Program Results", 9th AIAA Aviation Technology, Integration, and Operations Conference, 21-23 September 2009, Hilton Head South Carolina.

Sims, R., Taylor, M., Saddler, J. and Mabee, W. (2008), "From 1st to 2nd Generation Biofuel Technologies: An Overview of Current Industry and RD\&D Activities", International Energy Agency.

Sobie, B., (2010), "Salicornia Shortage Scuppers First Mexican Biofuels Flight", Flight International, 26 January - 1 February 2010, p 11.

Warwick, G., (2009), Green Day. Aviation Week \& Space Technology;1/5/2009, Vol. 170 Issue 1, p20, website: aviationweek.com

\section{Nomenclature}

$\tau_{c} \quad=$ compressor temperature ratio

$\dot{m}_{c} \quad=$ mass flow rate of core stream $(\mathrm{kg} / \mathrm{s})$

$\dot{m}_{F} \quad=$ mass flow rate of fan stream $(\mathrm{kg} / \mathrm{s})$ 


$$
\begin{array}{ll}
\tau_{\lambda} & =\text { ratio of burner exit enthalpy to ambient enthalpy } \\
\tau_{r} & =\text { ratio of total to static temperature of the free stream } \\
\dot{m}_{0} & =\text { total mass flow rate }(\mathrm{kg} / \mathrm{s}) \\
\dot{W}_{t} & =\text { turbine power (Watt) } \\
\tau_{t} & =\text { turbine temperature ratio } \\
\mathrm{C}_{\mathrm{p}} & =\text { heat capacity } \\
\mathrm{F} & =\text { thrust }(\mathrm{N}) \\
\mathrm{\gamma} & =\text { gamma (dimensionless) } \\
\mathrm{g}_{\mathrm{c}} & =\text { gravity constant } \\
\mathrm{T}_{\mathrm{t} 4} & =\text { turbine inlet temperature }(\mathrm{K}) \\
\mathrm{T}_{\mathrm{t} 5} & =\text { turbine outlet temperature }(\mathrm{K}) \\
\mathrm{V}_{0} & =\text { initial velocity }(\mathrm{m} / \mathrm{s}) \\
\mathrm{V}_{19} & =\text { fan exit velocity }(\mathrm{m} / \mathrm{s}) \\
\mathrm{V}_{9} & =\text { core exit velocity }(\mathrm{m} / \mathrm{s})
\end{array}
$$

\section{Definition, Acronyms and Abbreviations}

$$
\begin{array}{ll}
\text { B100 } & =\text { pure biofuel (100\% biofuel) } \\
\text { B50 } & =\text { mixture of } 50 \% \text { biofuel with } 50 \% \text { kerosene } \\
\text { BPR } & =\text { bypass pressure ratio (dimensionless) } \\
\mathrm{C} & =\text { carbon atom } \\
\text { CEA } & =\text { NASA chemical equilibrium with application } \\
\text { CME } & =\text { Canola methyl ester } \\
\text { CSPK } & =\text { Camelina bio-synthetic paraffinic kerosene } \\
\text { FAR } & =\text { Fuel air ratio } \\
\text { FPR } & =\text { fan pressure ratio (dimensionless) } \\
\text { H } & =\text { Hydrogen atom } \\
\text { H } & =\text { Hydrogen } \\
\text { HF } & =\text { Hog-fat } \\
\text { HPCPR } & =\text { high pressure compressor pressure ratio } \\
\text { HPT } & =\text { high pressure turbine (dimensionless) } \\
\text { IPCPR } & =\text { intermediate pressure compressor pressure ratio (dimensionless) } \\
\text { JSPK } & =\text { Jatropha bio-synthetic paraffinic kerosene } \\
\text { LHV } & =\text { low heating value (MJ/kg) } \\
\text { M } & =\text { mach number (dimensionless) } \\
\text { OPR } & =\text { overall pressure ratio (dimensionless) } \\
\text { PYTHIA } & =\text { Cranfield in-house engine performance computer tool } \\
\text { RRME } & =\text { Recycled rapeseed methyl ester } \\
\text { SFC } & =\text { specific fuel consumption } \\
\text { SME } & =\text { Soy methyl ester } \\
\text { TET } & =\text { turbine entry temperature (K) } \\
\text { TSFC } & =\text { thrust specific fuel consumption } \\
&
\end{array}
$$


$=$ mass flow rate $(\mathrm{kg} / \mathrm{s})$ 


\title{
Effects of biofuels properties on aircraft engine performance
}

\author{
Mazlan, Nurul Musfirah
}

Emerald Group Publishing Ltd.

Nurul Musfirah Mazlan, Mark Savill, Timos Kipouros, (2015) Effects of biofuels properties on aircraft engine performance, Aircraft Engineering and Aerospace Technology: An International Journal, Vol. 87, Iss. 5, pp437-442

http://dx.doi.org/10.1108/AEAT-09-2013-0166

Downloaded from Cranfield Library Services E-Repository 